\section{PROM-PRO Annual Conference at the Faculty of Transport and Traffic Sciences}

The PROM-PRO Conference is a scientific meeting and a part of the Program for stimulation of research and innovation at the Faculty of Transport and Traffic Sciences.

The final Conference was held on $23^{\text {rd }}$ January 2017 at the Faculty of Transport and Traffic Sciences. It presents a crucial part of a strategic framework which aims to improve the quality of research activities and increase the productivity in the field of traffic and transportation engineering.

The main purpose of the Program is to encourage the developmental and innovative character of scientific activity at the Faculty of Transport and Traffic Sciences by forming research groups of individuals who share a common interest. Moreover, by networking at the Faculty's level, with active participation and involvement of doctoral and post-doctoral students, and with completely independent funding by the Faculty, the scientific research should be directed towards international project applications. This was also a requirement for the research groups to continue their funding after the first year. Therefore, the Program was designed to allow a significant degree of freedom for researchers, as well as confidence and independence in their work.

PROM-PRO 2018 Conference offered respectable scientific work presented in the form of technical reports.

The aim of technical report Adapting the Railway System in the Integrated Passenger Transport (AR$S I P T)$ was to present the mechanisms of adaptation in an integrated railway passenger transport in the legal, organizational, technological, technical and economic terms (authors B. Abramovic et al.). The conclusion is that the railway is the backbone for organizing integrated passenger public system services.

The research of different markers which allow anonymous identification of vehicles was presented in the second paper called Vehicle Detection from Video in Bad Weather Conditions (authors M. Muštra et al.). During the period of project funding, the team managed to write and actively participate in writing of five different project proposals with different funding schemes, mostly financed by the EU, one of which has already been accepted. The total amount of funds applied for is around 21 million kuna.

By combining strategies aimed to reduce private car usage and strategies for increasing the attractiveness among other modes of transport (public transport, non-motorized transport), the improvements of transport system in general can be achieved. The third paper called Planning Sustainable Urban
Mobility Using Transport Demand Management (authors M. Slavulj et al.) deals with this phenomenon. The future work will be focused on developing sustainable urban mobility plans with particular interesting measures involving public transport and mobility management for large institutions.

The general purpose of the project The Use of Unmanned Aerial Vehicles in the Traffic Incident Management (authors P. Škorput et al.) was the expansion of the Faculty of Transport and Traffic Sciences research work in the field of unmanned aerial vehicles in ITS, namely, traffic control systems and incident situations management. The focus of the research was to find ways so as to extend the existing ITS applications to innovative functionalities and to propose a more efficient way of managing incidents in traffic by using unmanned aerial vehicles.

Modern methods for the reduction of the exhaust emissions are focused on advanced traffic control to decrease travel times and the number of stop-and-go actions. In the research presented in the report titled The Impact of Advanced Urban Traffic Control on Energy Efficiency (authors M. Vujić et al.), the application of adaptive traffic control on signalized intersections was considered and a simulation model of demonstration corridor in the city of Zagreb was made. The most important result was a simulation model of a real corridor in the city of Zagreb (Zagrebačka Avenue) and the calibration of the model with real traffic situation.

The Conference was also attended by the invited lecturer, Prof Joško Deur, Ph.D. from the Faculty of Mechanical Engineering and Naval Architecture, University of Zagreb. He presented the project Integration of Electric Vehicles in Energy and Transport Systems. Mr. Marko Helfrih from the Development Agency Zagreb presented the possibilities offered by the Agency to students and post-doctoral students as part of the start-up projects.

Generally, the results from everything that has been presented gives wind in our sails to continue supporting valuable scientific work, strengthening the research cooperation and delivering respectable results and project applications. Overall results fulfilled the purpose of the Program for stimulation of research and innovation at the Faculty of Transport and Traffic Sciences. Round Table SMART CITY

Assoc. Prof. Doris Novak, Ph.D.

Chairman of the Committee on Science and Projects Faculty of Transport and Traffic Sciences University of Zagreb 